\title{
Surgical Management of Craniopharyngiomas in the Pediatric Population
}

\author{
Gabriel Zada Edward R. Laws \\ Department of Neurosurgery, Brigham and Women's Hospital, Harvard Medical School, Boston, Mass., USA
}

\section{Key Words}

Craniopharyngioma $\cdot$ Craniotomy $\cdot$ Transsphenoidal $\cdot$

Hypopituitarism $\cdot$ Pediatric $\cdot$ Diabetes insipidus

\begin{abstract}
Background: Craniopharyngiomas (CPs) are benign, locally aggressive neoplasms that comprise approximately $10 \%$ of pediatric brain tumors. The role of surgical management for CPs is discussed in this review. Methods: A review of the goals and techniques associated with selected surgical approaches for the treatment of CPs in the pediatric population is provided. Results: CPs may be a cause of significant morbidity in children, requiring long-term, multimodal management by a team of specialists in order to optimize patient outcomes. Surgical intervention for CPs remains an important component of treatment, and depends upon establishing realistic and well-defined goals prior to any operation. Many transcranial and transsphenoidal approaches are available for approaching and resecting CPs. A summary of the rationale behind the timing and appropriateness of various surgical approaches, as well as associated benefits, pitfalls, and outcomes, is provided in this review. Conclusion: Consistent longitudinal management by an interdisciplinary team can alter the treatment course in patients with CPs from a debilitating, morbid or lethal condition to a chronic, survivable disease with functional adult livelihood. Excellent
\end{abstract}

\section{KARGER}

Fax +4161306 1234

E-Mail karger@karger.ch

www.karger.com
(C) 2010 S. Karger AG, Basel

$1663-2818 / 10 / 0741-0062 \$ 26.00 / 0$

Accessible online at:

www.karger.com/hrp outcomes in children with CPs are obtained only by close, frequent monitoring and by developing a keen sense of judgment regarding the appropriateness, timing and aggressiveness of any particular intervention.

Copyright $\odot 2010$ S. Karger AG, Basel

\section{Introduction}

Craniopharyngiomas (CPs) are epithelially derived, neoplastic lesions originating from squamous epithelial cell rests located along the axis of the primitive stomodeum. Although they are histologically benign tumors, they remain a major source of long-term morbidity due to their locally invasive behavior and potential for recurrence. In children, CPs comprise approximately $10 \%$ of all primary intracranial neoplasms $[1,2]$. The most common location in which CPs arise is the suprasellar region; however, they can also be encountered as purely intrasellar, third ventricular, or nasopharyngeal masses [3].

Headache and visual deficits are common clinical manifestations of these tumors occurring at any age. Because of their intimate anatomical association with the developing hypothalamic-pituitary axis and infundibulum, CPs frequently present with endocrine-related symptoms and signs, which in children often include growth retardation, sexual retardation, and obesity $[1$, 
$3-5]$. In addition, CPs arising in the pediatric population commonly cause obstruction of the cerebrospinal fluid outflow pathways, manifesting as hydrocephalus and elevated intracranial pressure [2]. The two major histopathological subtypes of CPs are the adamantinomatous and squamous-papillary varieties. In children, the adamantinomatous subtype is by far the more common variation, and is characterized by both solid and cystic components and calcification in the majority of patients.

\section{Surgical Management of CPs}

Achieving optimal outcomes using multimodal treatment strategies in children with CPs often depends upon the appropriate timing and sequence of various management options, which include careful observation, surgical resection, medical management, brachytherapy, or adjunctive radiation therapy/radiosurgery. Unfortunately, nonsurgical options for CPs have provided limited benefits as primary interventions, while incurring their own set of risks, and are therefore commonly reserved as adjunctive means of therapy following surgical management.

Establishing appropriate and realistic goals of surgery is a critical step prior to the operative planning in any patient with a CP. The best long-term outcomes in patients with CPs have been reported following surgical intervention with gross total resection of the tumor, which remains the preferred surgical goal when it can be safely achieved with minimal morbidity [6]. Intraoperatively, many CPs are observed to exhibit invasion of or dense adhesion to the optic chiasm, vessels of the Circle of Willis, or surrounding brain tissue, which may preclude a gross total resection of the tumor. In some CPs, such as those with extensive hypothalamic involvement, or in patients with recurrent or previously-irradiated lesions, the surgical objective may instead be partial tumor debulking, drainage of the cystic component of the tumor, or a biopsy of the lesion [7].

Historically, several surgical approaches have been successfully utilized for the treatment of CPs, including a variety of transcranial and transsphenoidal skull base approaches. No one surgical technique can be considered the 'best approach' for all patients. Each patient is best served by the formulation of a tailored, individualized surgical plan that aims to realistically and safely achieve the proposed operative goals. Furthermore, it is not uncommon for young patients with CPs to require multiple operations over the course of their lifetimes, often via dif-

Surgery for Craniopharyngiomas in Children ferent approaches. The risk profile associated with any operative approach for resection of a CP may include infection, hemorrhage, visual loss, hypopituitarism (including diabetes insipidus), hypothalamic obesity, and neurological sequelae secondary to vascular injury. The majority of patients have some degree of anterior hypopituitarism following surgery, mandating the need for long-term hormonal replacement and close observation by an endocrinologist [2-4]. Furthermore, the risk of diabetes insipidus following surgical resection has been reported as $50-65 \%[1,2,5,8]$.

As part of the comprehensive surgical management of pediatric patients with CPs, a subset of children presenting with hydrocephalus will require perioperative placement of a cerebrospinal fluid diverting shunt, such as a ventriculoperitoneal shunt. This can be performed either before or after the operation for tumor removal, depending on the likelihood for improvement of hydrocephalus following tumor resection.

\section{Transcranial Approaches to CPs}

The selection of a surgical approach for the treatment of CPs is in large part dictated by the size of the tumor and its location relative to critical neurovascular structures. In particular, the location of the tumor relative to the optic apparatus, hypothalamus, third ventricle, internal carotid arteries, and pituitary stalk plays a major role in favoring a selected surgical approach. Tumors with a location that is primarily prechiasmatic (anterior to the optic chiasm), or those with significant suprasellar extension into the hypothalamus or ventricular system, may be preferentially approached via one of several transcranial operations (fig. 1). These surgical techniques have traditionally included the subfrontal (under the frontal lobe) (fig. 2), pterional-transsylvian (through the Sylvian fissure), interhemispheric-transcallosal (between the cerebral hemispheres), and transcorticaltransventricular (through the frontal cortex and lateral ventricle) approaches.

Although transcranial procedures generally offer excellent visualization and tumor exposure, they may require significant bony removal and/or brain retraction in some cases. For large tumors that arise in a primarily retrochiasmatic (posterior to the optic chiasm) location, a more extensive skull base operation, such as a transpetrosal (through the petrous bone and apex) approach, may be required to achieve improved exposure for resection. 
Fig. 1. Sagittal (a) and coronal (b) gadolinium-enhanced MRI showing a child with a sellar and suprasellar mixed cystic and solid CP. Sagittal (c) and coronal (d) MRI following interhemispheric-transcallosal resection of the tumor. A gross total tumor resection was achieved.
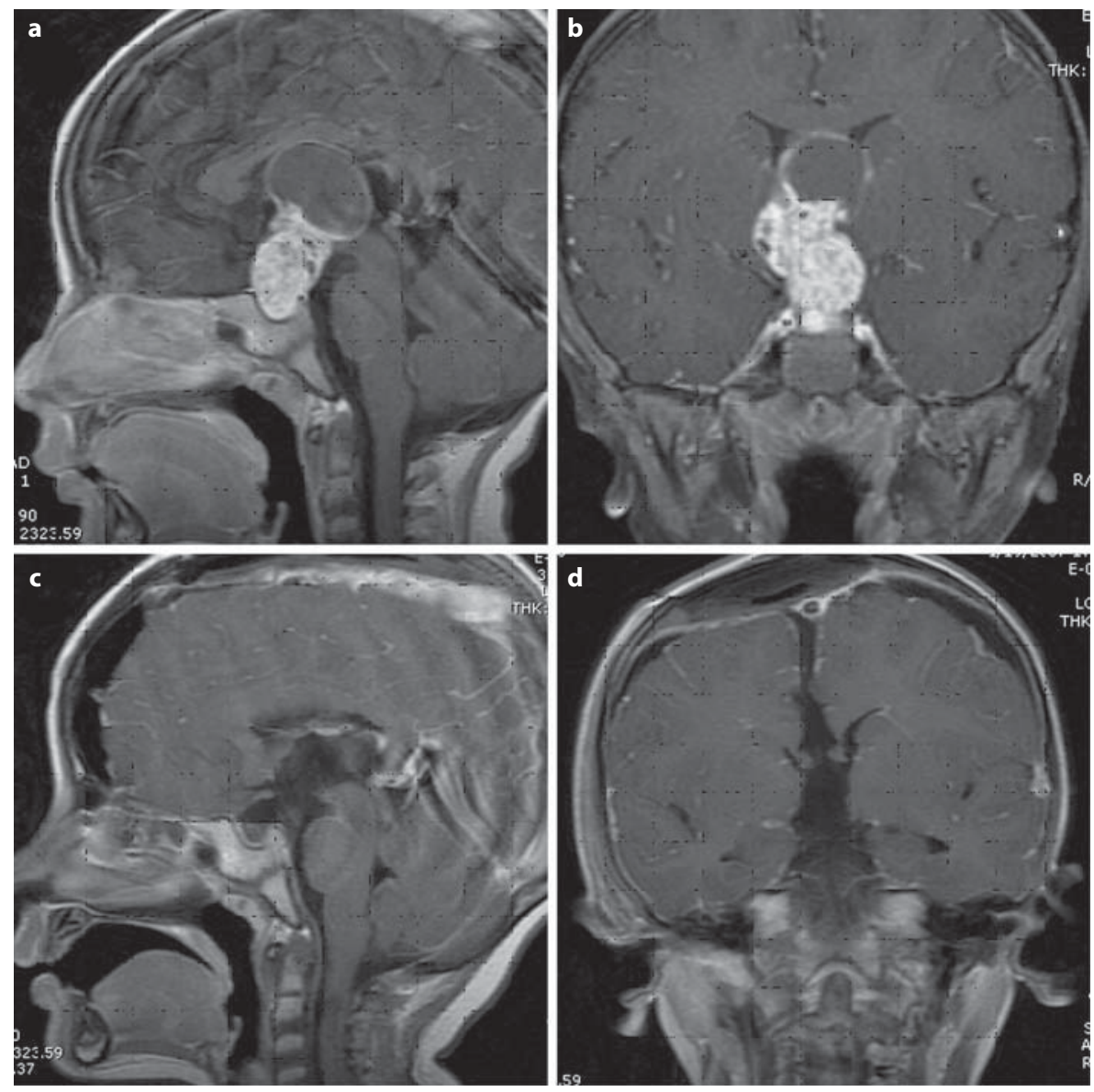

\section{Transsphenoidal Approaches to CPs}

Many CPs with a large intrasellar component, or a subset with a retro-chiasmatic location, may be preferentially amenable to resection via a less invasive transsphenoidal skull base approach (fig. 3). The transsphenoidal procedure was first successfully used by Schloffer in 1906, yet subsequently fell out of favor as the preferred surgical approach to the sellar region for several decades. The approach was reintroduced in the 1950s and 1960s by Guiot and Hardy, and has since continued to evolve as the preferred approach for selected patients with CPs. Modifications of the approach, including the extended transsphenoidal operation, may improve surgical access and exposure of the suprasellar and retrosellar region and the ability to achieve more extensive tumor resection. Another benefit of transsphenoidal surgery is that it offers a midline approach and tumor exposure, which may be beneficial for lesions located along the midline, such as CPs. Finally, transphenoidal operations may obviate the need for brain retraction that is required in some transcranial operations. Although an additional risk of the transsphenoidal approach is cerebrospinal fluid leakage, modern techniques used for reconstructing the skull base have reduced the incidence of this particular complication to less than $10 \%$ in the majority of current series [1].

Technological advances in the surgical arena over the past several decades, including the operating microscope, advanced neuroimaging and neuronavigation instruments, and neuroendoscopy, have facilitated optimization of tumor resection while minimizing surgical complications. In recent years, neuroendoscopic skull base techniques have provided improved panoramic visualization via a small endonasal aperture, which may be ideal for approaching these lesions in children. Another consideration in the pediatric population is the degree of pneumatization of the sphenoid sinuses: children with non-pneumatized paranasal sinuses may require a greater degree of bony removal and drilling as part of the surgical approach. 


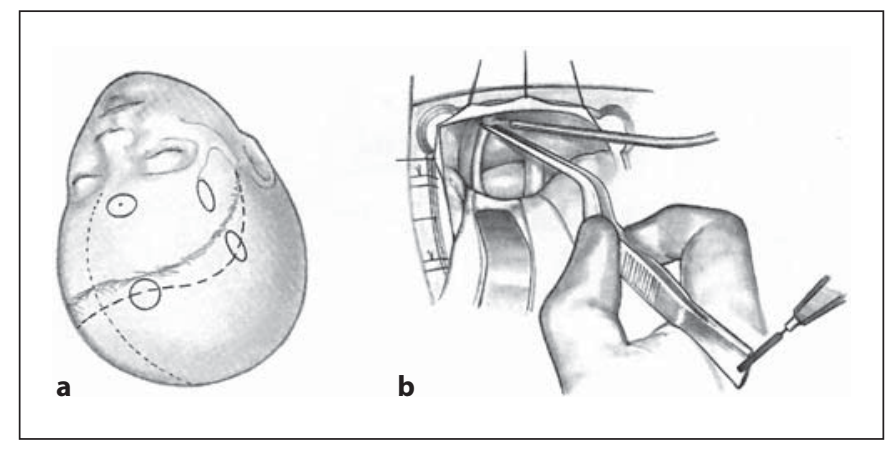

Fig. 2. a Figure depicting the incision and craniotomy of a right subfrontal approach to a CP in a child. $\mathbf{b}$ Retraction of the frontal lobe allows visualization of the tumor near the optic apparatus and internal carotid artery. Figure from Shillito and Madsen [9] (permission requested).

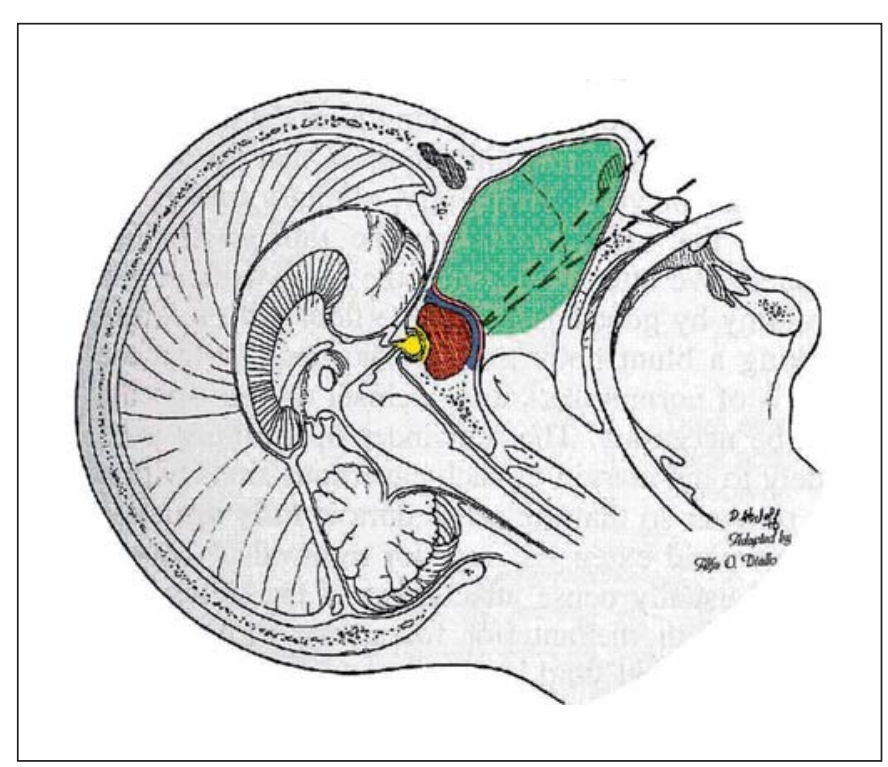

Fig. 3. Schematic depicting the steps of the transsphenoidal approach to the sellar region. The steps to this region include the nasal phase (green), sphenoid phase (red), and sellar phase (yellow).

\section{Surgical Outcomes, Recurrence, and Adjunctive Therapy}

A variety of surgical series have reported gross total resection rates of CPs in 59-95\% of patients $[1,5,6,10]$. Longitudinal studies following gross total resection, however, have reported long-term recurrence rates of 10 $50 \%$, mandating the requirement for sequential imaging

and close follow-up in all patients $[1,2,5,6]$. A subtotal resection has been clearly associated with higher degrees of clinical recurrence and disease progression. This, however, can be partially offset or delayed by postoperative adjunctive radiation therapy $[2,6,10]$. Radiation therapy, however, confers its own set of risk factors, including hypopituitarism, visual loss, and cognitive dysfunction, especially in children less than 9 years old.

More recently, attempts have been made to treat residual or recurrent CPs with stereotactic radiosurgery modalities, which have been associated with lower rates of visual loss and endocrine dysfunction than external beam radiation therapy for lesions located more than $3 \mathrm{~mm}$ from the optic apparatus. Not enough long-term outcome data, however, are currently available to support this modality as the gold standard technique for postoperative radiation. Newer methods of fractionated intensity modulated radiotherapy have been quite successful in achieving tumor control while preserving quality of life [11].

\section{Conclusions}

Optimized long-term management of children with CPs requires an interdisciplinary effort, composed of a team of dedicated endocrinologists, ophthalmologists, neurosurgeons, neuroradiologists, neuropathologists, and radiation oncologists who are experienced in treating patients with such lesions. Many times, consistent longitudinal management as a result of such an interdisciplinary effort can alter the treatment course in patients with CPs from a debilitating, morbid, or lethal condition to a chronic, survivable disease with functional adult livelihood. Excellent outcomes in children with CPs are obtained only by close, frequent monitoring and developing a keen sense of judgment regarding the appropriateness, timing, and aggressiveness of any particular intervention.

References

Horm Res Paediatr 2010;74:62-66 
3 Jagannathan J, Dumont AS, Jane JA Jr, Laws ER Jr: Pediatric sellar tumors: diagnostic procedures and management. Neurosurg Focus 2005; 18:E6.

-4 Albright AL, Hadjipanayis CG, Lunsford LD, Kondziolka D, Pollack IF, Adelson PD: Individualized treatment of pediatric craniopharyngiomas. Childs Nerv Syst 2005;21: 649-654.

5 Elliott RE, Hsieh K, Hochm T, BelitskayaLevy I, Wisoff J, Wisoff JH: Efficacy and safety of radical resection of primary and recurrent craniopharyngiomas in 86 children. J Neurosurg Pediatr 2010;5:30-48.
6 Weiner HL, Wisoff JH, Rosenberg ME, Kupersmith MJ, Cohen H, Zagzag D, Shiminski-Maher T, Flamm ES, Epstein FJ, Miller DC: Craniopharyngiomas: a clinicopathological analysis of factors predictive of recurrence and functional outcome. Neurosurgery 1994;35:1001-1010, discussion 1010-1011.

7 Puget S, Garnett M, Wray A, Grill J, Habrand JL, Bodaert N, Zerah M, Bezerra M, Renier D, Pierre-Kahn A, Sainte-Rose C: Pediatric craniopharyngiomas: classification and treatment according to the degree of hypothalamic involvement. J Neurosurg 2007; 106:3-12.

8 Honegger J, Buchfelder M, Fahlbusch R: Surgical treatment of craniopharyngiomas: endocrinological results. J Neurosurg 1999;90: 251-257.
9 Shillito J, Matson DD: An Atlas of Pediatric Neurosurgical Operations. Philadelphia, WB Saunders, 1982.

10 Van Effenterre R, Boch AL: Craniopharyngioma in adults and children: a study of 122 surgical cases. J Neurosurg 2002;97:3-11.

11 Merchant TE, Kiehna EN, Sanford RA, Mulhern RK, Thompson SJ, Wilson MW, Lustig RH, Kun LE: Craniopharyngioma: the St. Jude Children's Research Hospital experience 1984-2001. Int J Radiat Oncol Biol Phys 2002;53:533-542. 